九州大学学術情報リポジトリ

Kyushu University Institutional Repository

\title{
Consumer Willingness to Pay for Food Safety in Shanghai China : A Case Study of Gap-Certified Mi lk
}

Chen, Tinggui

College of Economics and Management, Shanghai Ocean University

Song, Min

Institute of Agricultural Resources and Regional Planning, Chinese Academy of Agricultural Sciences

Nanseki, Teruaki

Faculty of Agriculture, Kyushu University

Takeuchi, Shigeyoshi

Faculty of Agriculture, Kyushu University

他

https://doi.org/10.5109/27380

出版情報: 九州大学大学院農学研究院紀要. 58 (2)，pp.467-473，2013-09. Faculty of Agriculture， Kyushu University

バージョン :

権利関係 : 


\title{
Consumer Willingness to Pay for Food Safety in Shanghai China: A Case Study of Gap-Certified Milk
}

\section{Tinggui CHEN ${ }^{1}$, Min SONG ${ }^{2}$, Teruaki NANSEKI ${ }^{3 *}$, Shigeyoshi TAKEUCHI ${ }^{3}$, Hui ZHOU ${ }^{4}$ and Dongpo $\mathbf{L I}^{5}$}

\author{
Laboratory of Agricultural and Farm Management, Division of Agricultural and Resource Economics, \\ Department of Agricultural and Resource Economics, Faculty of Agriculture, \\ Kyushu University, Fukuoka 812-8581, Japan \\ (Received April 26, 2013 and accepted May 9, 2013)
}

\begin{abstract}
From the melamine incident of Sanlu milk powder in 2008 to the illegal food additives incident of Bright Dairy in 2012, the food safety problems of milk have been plaguing the Chinese National diet. This paper analyzed consumer willingness to pay for food safety in Shanghai China through a case study of GAP certified milk. Shanghai consumers were selected for the survey, in which a contingent valuation was conducted. The study found that consumers were willing to pay for GAP certificated milk at an average price of $2.38 \mathrm{RMB} / 250 \mathrm{ml}, 18.5 \%$ higher than the ordinary milk price. The results of the binary logistic regression model showed that the factors that affect consumers' willingness to pay include gender, income, the price of GAP certified milk and whether there were preschoolers in the household as statistically significant.
\end{abstract}

Key words: food safety, GAP, milk, WTP

\section{INTRODUCTION}

China's food safety incidents emerge continuously, and cover a very wide range of circumstances. These incidents are all-encompassing. The particular concerns of this paper are dairy safety incidents. In 2004 in Fuyang, Anhui province there were more than 13 babies who died due to drinking infant formula powder lacking in protein content. In 2008 the melamine incident of Sanlu milk powder resulted in three babies dying and hundreds of babies suffering from kidney stones. From June to September of 2012 food safety incidents occurred five times in Bright Dairy, which is one of the largest dairy production and sales enterprises in China. Domestic dairy safety incidents occur frequently, resulting in many consumers turning to imported dairy products. Foreign dairy giants took this opportunity to gain a foothold in the Chinese dairy market. This is especially apparent with infant milk powder, pure milk with high-temperature sterilization, and as well as cheese which is becoming popular with Chinese consumers. However with the nuclear leak occurring in Japan, the exposure of imported brands to milk safety risks, and high prices make it difficult to depend upon foreign products.

Because of China's huge population, there is the great demand for dairy products. It is neither realistic

\footnotetext{
Colloge of Economics and Management, Shanghai Ocean University, P. R. China

Institute of Agricultural Resources and Regional Planning, Chinese Academy of Agricultural Sciences, P. R. China

Faculty of Agriculture, Kyushu University

${ }^{4}$ Institute of Agricultural Economics and Development, Chinese Academy of Agricultural Sciences, P. R. China

${ }^{5}$ Institute of Rural Economics, Hebei Academy of Social Sciences, P. R. China

* Corresponding author (E-mail: nanseki@agr.kyushu-u.ac.jp)
}

nor possible to rely on foreign markets in this case. Improving the quality of domestic dairy products will be a fundamental solution to Chinese dairy food safety issues. On the one hand there is a huge demand for safe food; on the other hand consumer confidence in the safety level of domestic products is lacking. Information and consumer knowledge does exist for the consumer food safety market. If the market is able to provide safer dairy products, what will the consumer demand be? What will be the willingness to pay (WTP) of the consumers for the product safety of dairy goods? Our study will try to access and analyze the problems.

There are many papers that have studied WTP on food safety in China. Research methods include binary logistic regression models (Yingheng Zhou and Xiajia Peng 2006, Liu jundi et al., 2009, and Wang Zhigang et al., 2012), hierarchical models (Zeng Yingchu et al., 2008), Integrating with the choice modelling (CM) technique and the multinomial logit model (Hui Zhou and Teruaki Nanseki, 2013). Study objects include low-residue vegetables (Yingheng Zhou and Xiajia Peng, 2006), food additives (Zeng Yingchu et al., 2008), organic pork (Liu jundi et al., 2009), safe milk (Wang Zhigang et al., 2012), and milk with certification of traceability (Hui Zhou and Teruaki Nanseki, 2013). Research areas mainly include the big cities, such as Beijing, Shanghai, Nanjing, Tianjin. There is a big gap in consumer's WTP for food safety. Price overflow is from 10\% (Wang Zhigang et al., 2012) to 335\% (Yingheng Zhou and Xiajia Peng, 2006). As the main influencing factors of WTP, gender, education, income, prices, consumer awareness and evaluation will impact the consumers WTP.

In the above studies Zhou and Peng (2006) analyzed the consumers' WTP, considered the cost of pollutionfree vegetable production, and pointed out the real possibility of safe vegetable markets in China. Other stud- 
ies have stayed on the consumers' WTP, with no further consideration of safe food supply. Wang et al. (2012) doesn't clearly define safe milk. So there is a need for further study.

Because of the above factors, this paper selects the pure milk certified Good Agricultural Practice (GAP) (hereinafter referred GAPmilk) as the object of study, based on the consumer questionnaire survey in Shanghai, analyzing WTP for food safety and its influencing factors by using binary logistic regression models. Finally considering the cost of the GAP certification we analyzed the possibility of the GAPmilk market from both sides of supply and demand.

\section{FIELD SURVEY AND DEMOGRAPHIC CHARACTERISTICS}

The data is from a questionnaire interview in Shanghai, done by food safety research group of Kyushu University East Asia Environmental Research Institutions in December 2011. Twenty students from Shanghai Ocean University who live in Shanghai were selected to administer the questionnaire. After training, they interviewed their own parents, colleagues and friends as well as relatives of the parents, and near residents. Upon surveying twenty students, the study required the data collectors to fill in their own name and the respondents' residential addresses as thoroughly as possible to ensure the authenticity of the questionnaire. We obtained 318 completed surveys, of which 303 were valid questionnaires. We chose milk as the research subject, not only because the results could be compared with Wang et al. (2012)'s result, but also compared with other international studies, as milk a universal food. In addition, it would be conducive to comparisons with international studies also choosing the international metropolis of Shanghai as an investigation area.
The statistical characteristics of the surveyed consumers are summarized in Table 1. From a gender point of view, the male respondents accounted for $44.88 \%$, while females accounted for $55.12 \%$. Usually women pay more attention to food consumption and food safety than men. Therefore, the gender compositions of the survey sample contribute to realistic situations. From the age structure point of view, the respondents are mainly concentrated in the age grouping of 20-49 years, which accounted for $82 \%$ of the study. The proportion of the three age groups of 20-29, 30-39, 40-49 years is almost the same, $29.47 \%, 27.15 \%$, and $25.83 \%$, respectively. For the level of education, having a junior/middle school education or less of an education accounted for only $12 \%$ of the study. However, college or more education accounted for $53 \%$ of the study. This shows a high education level of the sample consumers. For the income level of the respondent's family, an annual income of less than $35,000 \mathrm{RMB}$ accounted for $20.07 \%$ of the study, 35000-70000 RMB accounted for $26.87 \%$ of the study, 70000-150000 RMB accounted for $34.69 \%$ of the study, and an annual income of more than 150,000 RMB accounted for $18.37 \%$ of the study. The revenue structure is in line with the current income levels in Shanghai, and is a strong representation of the population of the city. We expect that knowledge of agriculture, food or medical disciplines will have an impact on consumers' food safety's WTP. The study showed that $14.52 \%$ of the respondents possess such relevant knowledge, while $85.48 \%$ of the respondents lack such experiences. We also expect that if the household has preschoolers, students or elders over the age of 60 , there will be a positive impact on food safety's WTP. The sample data shows that $7.1 \%$ of all households have preschoolers, $27.42 \%$ of the households contain elderly people over the age of 60 , and $48.39 \%$ of the families have students.

Table 1. Demographic characteristics of the surveyed consumers

\begin{tabular}{|c|c|c|c|c|c|c|c|}
\hline \multicolumn{2}{|c|}{ Category } & \multirow{2}{*}{$\begin{array}{c}\text { Valid N } \\
9\end{array}$} & \multirow{2}{*}{$\begin{array}{l}\% \\
2.98\end{array}$} & \multicolumn{2}{|c|}{ Category } & \multirow{2}{*}{$\frac{\text { Valid N }}{44}$} & \multirow{2}{*}{$\begin{array}{c}\% \\
14.52\end{array}$} \\
\hline \multirow{6}{*}{ Age } & $<20$ & & & \multirow{2}{*}{$\begin{array}{l}\text { Background in agriculture, } \\
\text { food and medicine }\end{array}$} & Yes & & \\
\hline & $20-29$ & 89 & 29.47 & & No & 259 & 85.48 \\
\hline & 30-39 & 82 & 27.15 & \multirow{2}{*}{ Gender } & Male & 136 & 44.88 \\
\hline & $40-49$ & 78 & 25.83 & & Female & 167 & 55.12 \\
\hline & $50-59$ & 34 & 11.26 & \multirow{3}{*}{ Household information } & Preschooler & 22 & 7.10 \\
\hline & $60 \leq$ & 10 & 3.31 & & Student & 150 & 48.39 \\
\hline \multirow{6}{*}{$\begin{array}{l}\text { Education } \\
\quad \text { level }\end{array}$} & Primary school and less & 7 & 2.34 & & Elderly over 60 years & 85 & 27.42 \\
\hline & Junior middle school & 29 & 9.70 & \multirow{5}{*}{ Annual Income $\left(\mathrm{RMB}^{\mathrm{a}}\right)$} & $<35000 \mathrm{RMB}$ & 59 & 20.07 \\
\hline & High school & 106 & 35.45 & & 35000-70000 RMB & 79 & 26.87 \\
\hline & College & 124 & 41.47 & & 70000-150000 RMB & 102 & 34.69 \\
\hline & Postgraduate & 33 & 11.04 & & 150000-300000 RMB & 45 & 15.31 \\
\hline & & & & & $300000 \mathrm{RMB} \leqslant$ & 9 & 3.06 \\
\hline
\end{tabular}

Note: ${ }^{\text {a }} R M B$ is the major currency unit in China, and 1 US $\$$ equals to $6.30 R M B$ by the end of 2011.

Source: field survey by the authors 


\section{CONSUMER'S AWARENESS AND EVALUATION OF FOOD SAFETY}

Consumer's awareness and evaluation of food safety will affect WTP for food safety (according to Ritson and $\mathrm{Li}, 1998)$. Given this premise, the questionnaire contains the contents of Fig. 1-Fig. 7. The questionnaire results showed that $40.40 \%$ (122) of respondents are very concerned about food safety, 45.36\% (137) of respondents are concerned, which makes a total of $85.76 \%$ (Fig. 1). So we can say that the vast majority of consumers are concerned about food safety. Of the respondents $68.44 \%$ (206) believe that environmental pollution and food safety are related, and $21.59 \%$ (65) of the respondents believe that environmental pollution and food safety are possibly related (Fig. 2). This shows that while consumers are concerned about food safety, the majority are also concerned about environmental pollution. Of the respondents $52.46 \%$ (160) believe that the industrial pollution has the greatest impact on food safety, while $32.13 \%$ (98) of the respondents believe that the agricultural pollution has the largest impact upon the food safety. Only $10.16 \%$ of the respondents believe that the domestic pollution has the greatest on the food safety (Fig. 3).

As to the question of "Do you worried about the safety of milk?" $32.56 \%$ (98) of the respondents are very worried, $32.56 \%$ (98) of the respondents are wor-

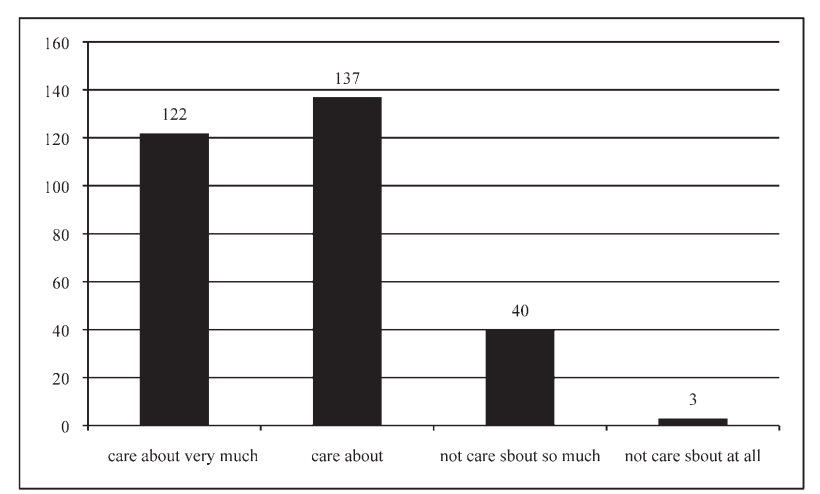

Fig. 1. Consumer perceptions on food safety (302 valid responses) Source: field survey by the authors.

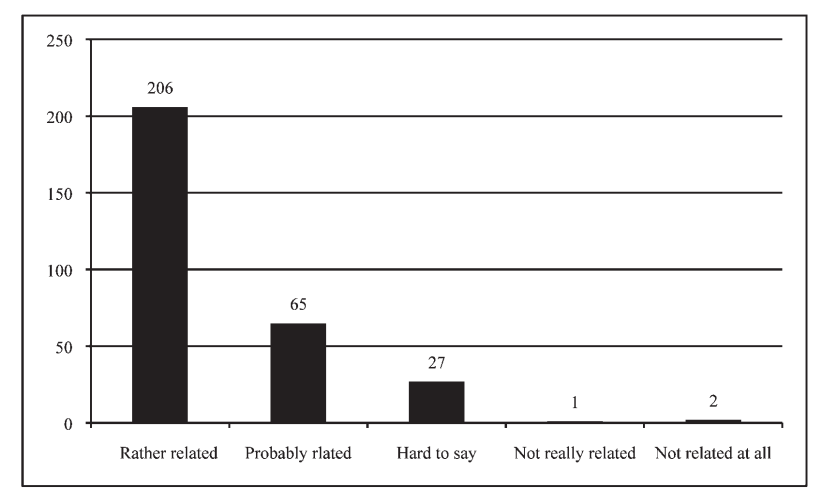

Fig. 2. Relevance of the food safety and pollution (301 valid responses)

Source: field survey by the authors. ried. Only 4\% (12) of the respondents are not worried (Fig. 4). This indicates that most consumers are not confident with milk safety. Of the respondents $51.14 \%$ (157) think processing is the most risky procedure or stage of food supply, $21.50 \%$ (66) of the respondents think agricultural production is the most risky procedure or point of food supply, and $14.66 \%$ (45) of the respondents think transportation of raw milk is the most risky procedure or stage of food supply (Fig. 5) Consistent with the detection of the milk safety incidents, most consumers think that milk production and processing stages are the key point of safety control. Of

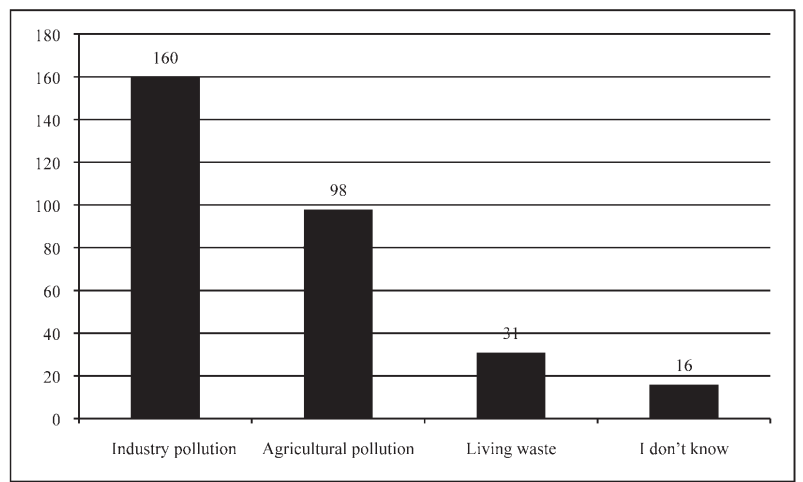

Fig. 3. Pollution effecting most food safety (305 valid responses) Source: field survey by the authors.

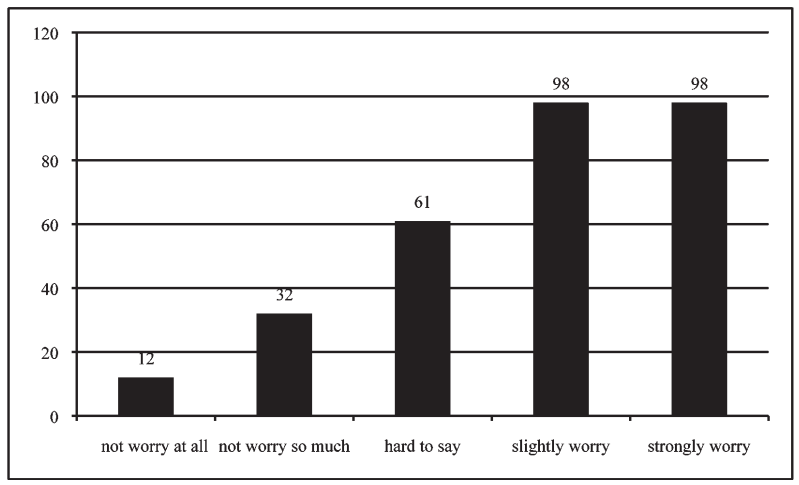

Fig. 4. Consumer perceptions on milk safety (301 valid responses) Source: field survey by the authors.

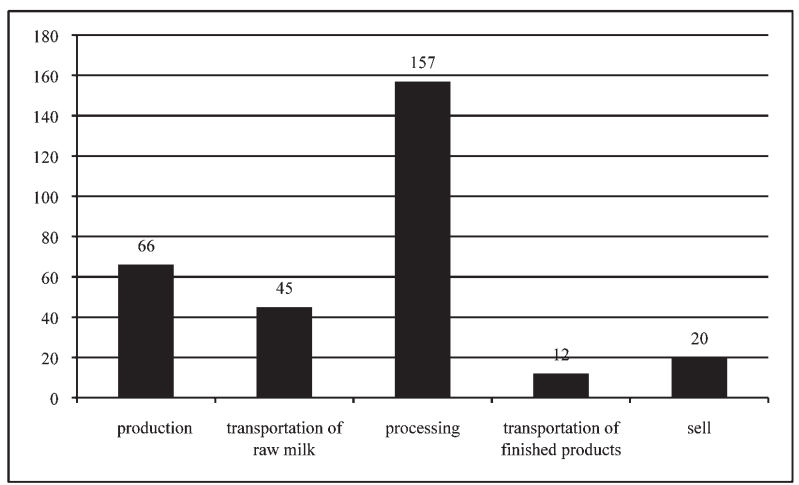

Fig. 5. Consumers' awareness on the most risky stage in food supply

Source: field survey by the authors. 


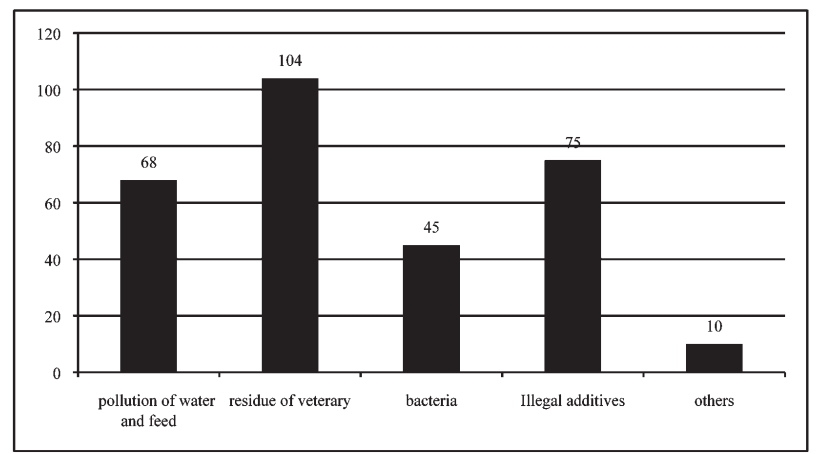

Fig. 6. Most important factor causing milk safety problem (310 valid responses)

Source: field survey by the authors.

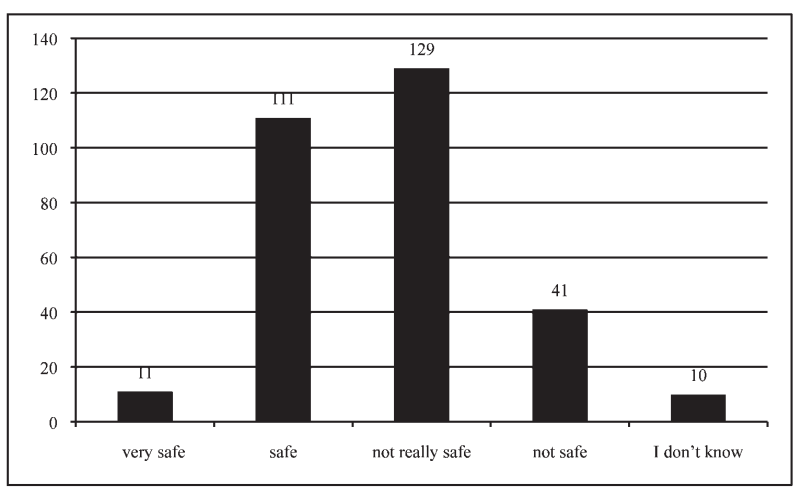

Fig. 7. Evaluation on food safety situation at present (302 valid responses)

Source: field survey by the authors.

the respondents $33.55 \%$ (104) think that the residues of antibiotics and hormones are the most important factors influencing the safety of milk, 24.19\% (75) of the respondents believe that unknown substances being illegally added are a problem with milk safety, and $21.94 \%$ (68) of the respondents believe that pesticides and heavy metal contamination are major problem with the safety of milk (Fig. 6). Corresponding with previous issues, most consumers believe that illegally adding unknown substances in the processing stage, as well as adding pesticides and antibiotics in the production stage is the main factors causing milk safety problems.

We also asked "How do you evaluate the food safety level of your recent purchase?" Of these results $42.72 \%$ (129) of the respondents think it is not very safe, $13.58 \%$ (41) of the respondents believe it is not safe, which combined for a total of $56.3 \%$. Of the remaining respondents $36.75 \%$ (111) feel it is safe. Only $3.64 \%$ (11) of the respondents felt the food safety level of the milk was very safe.

\section{STATISTICAL ANALYSIS OF CONSUMERS' WTP TO GAPMILK}

Only $5 \%$ of respondents are very familiar with GAP, $16 \%$ of respondents generally understand GAP, 35\% of respondents don't know the specific content of GAP but
Table 2. Consumers' WTP

\begin{tabular}{llcrc}
\hline \multicolumn{1}{l}{ Price } & $\begin{array}{c}\text { Premium } \\
\text { Ratio }\end{array}$ & Valid N & $\%$ \\
\hline Initial price & 2 RMB/250 ml & $0 \%$ & & \\
& No buy & & 14 & 4.67 \\
Random Inquiry & $2 \mathrm{RMB} / 250 \mathrm{ml}$ & $0 \%$ & 123 & 41.00 \\
& $2.3 \mathrm{RMB} / 250 \mathrm{ml}$ & $15 \%$ & 91 & 30.33 \\
& $2.7 \mathrm{RMB} / 250 \mathrm{ml}$ & $35 \%$ & 35 & 11.67 \\
& $3.2 \mathrm{RMB} / 250 \mathrm{ml}$ & $60 \%$ & 22 & 7.33 \\
& $3.8 \mathrm{RMB} / 250 \mathrm{ml}$ & $90 \%$ & 9 & 3.00 \\
& $4.5 \mathrm{RMB} / 250 \mathrm{ml}$ & $125 \%$ & 3 & 1.00 \\
& $6.0 \mathrm{RMB} / 250 \mathrm{ml}$ & $200 \%$ & 3 & 1.00 \\
& & & 300 & 100 \\
\hline
\end{tabular}

Source: field survey by the authors.

have heard of it, and 44\% had never heard of GAP. Most consumers are unfamiliar with GAP. After a detailed explanation of GAP, and strengthening information of GAP, we asked the respondents about their WTP to GAPmilk. We set the target for a box of $250 \mathrm{ml}$ of pure milk. On the basis of pre-research, the market price of ordinary milk (initial price B0) is set to $2 \mathrm{RMB} / 250 \mathrm{ml}$. Random inquiry price $(\mathrm{Br})$ are $2.3 \mathrm{RMB} / 250 \mathrm{ml}$, $2.7 \mathrm{RMB} / 250 \mathrm{ml}, \quad 3.2 \mathrm{RMB} / 250 \mathrm{ml}, \quad 3.8 \mathrm{RMB} / 250 \mathrm{ml}$, $4.5 \mathrm{RMB} / 250 \mathrm{ml}$, and $6.0 \mathrm{RMB} / 250 \mathrm{ml}$. The respondents' selection results are shown in Table 2. Of these $30.33 \%$ of the respondents are willing to buy at the price of $2.3 \mathrm{RMB} / 250 \mathrm{ml}, 11.67 \%$ of the respondents for $2.7 \mathrm{RMB} /$ $250 \mathrm{ml}, 7.33 \%$ of the respondents for $3.2 \mathrm{RMB} / 250 \mathrm{ml}$, $3.0 \%$ of the respondents for $3.8 \mathrm{RMB} / 250 \mathrm{ml}$. Consumers' WTP decreased gradually, but significantly, with increasing prices. Of these respondents $41 \%$ of respondents are willing to buy only at the original price, and there are $4.67 \%$ of the respondents who are not willing to buy. These consumers may primarily be composed of people who think current food safety situation is adequate and low-income people.

After excising the 14 respondents who were not willing to buy, consumers were willing to pay for GAP milk at an average price of $2.30 \mathrm{RMB} / 250 \mathrm{ml}$. Consumers were willing to pay an additional $0.30 \mathrm{RMB} / 250 \mathrm{ml}$ for food safety, which will account for $15 \%$ of the price of regular milk.

\section{EMPIRICAL MODEL WITH VARIABLE SELECTION}

\section{Model selection}

Contingent valuation method (CVM) is adopted to reveal consumers' preferences, through an empirical model to explore consumers' WTP for GAPmilk. Y represents the consumers' choice. If consumers are willing to consume GAPmilk, $\mathrm{Y}=1$; Conversely, $\mathrm{Y}=0$. The BID represents the additional price that consumers are willing to pay for GAPmilk. P represents the price of regular milk. X represents other factors affecting consumer 
choice except price, this would include gender, income, consumers' awareness and evaluation for food safety etc. The symbol $\varepsilon$ is a random error term, and $\alpha, \beta$, and $\lambda$ are parameters to be estimated. The utility of GAPmilk and ordinary milk are $\mathrm{U}_{\mathrm{Y}=1}\left(\mathrm{X}, \mathrm{BID}, \varepsilon_{1}\right)$ and $\mathrm{U}_{\mathrm{Y}=0}\left(\mathrm{X}, \mathrm{P}, \varepsilon_{0}\right)$, respectively. If and only if $\mathrm{U}_{\mathrm{Y}=1} \geq \mathrm{U}_{\mathrm{Y}=0}$, will the consumes choose to consume GAPmilk. Let $\mathrm{U}^{*}=\mathrm{U}_{\mathrm{Y}=1}-\mathrm{U}_{\mathrm{Y}=0}$, we can get the probability equation that consumers choose to consume $\operatorname{GAPmilk}(\mathrm{Y}=1)$ :

$$
\mathrm{P}(\mathrm{Y}=1)=\mathrm{P}\left(\mathrm{U}^{*} \geq 0\right)=\mathrm{P}\left(\mathrm{U}_{\mathrm{Y}=1} \geq \mathrm{U}_{\mathrm{Y}=0}\right)
$$

Due to $\varepsilon_{1}$ and $\varepsilon_{0}$ obeying the Weibull distribution, the equation can be set to linear logistic model through the transformation.

$$
\ln \left[\frac{P\left(Y_{1}\right)}{P\left(Y_{0}\right)}\right]=\alpha+\beta \mathrm{X}+\lambda B I D
$$

Assuming the additional average prices that consumers are willing to pay for GAPmilk is E (WTP), and then E (WTP) may be expressed as:

$$
\mathrm{E}(\mathrm{WTP})=-\frac{\alpha+\beta E(\mathrm{X})}{\lambda}
$$

If the $\alpha, \beta, \lambda$ coefficient values derived from the formula (1) and the mean value of the $\mathrm{X}$ variable are substituted into the formula (2), we can obtain the additional average prices that consumers are willing to pay for GAPmilk.

\section{Variable selection and description}

Drawing upon existing research results, this paper selected five factors as variables to reflect the individual characteristics of consumers; this includes gender, level of education, annual household net income, whether the household has preschoolers, and whether the household has elderly people over the age of sixty. Generally women are more concerned with health issues than men, and therefore have a relatively higher WTP for GAPmilk. Consumers with a higher level of education and the higher average household income will be willing to pay a greater price for GAPmilk. Those households with preschooler or elders over the age of 60 will be willing to pay to GAPmilk higher than the household without such special populations.

Price is an important factor affecting the consumer decision-making. This paper selects a higher price into the econometric model which consumers are willing to pay for GAPmilk, and expects the price negatively related to the WTP.

This study selects two indicators. One is consumer awareness of food safety risks, and the other is the riskiest procedure or stage of the food supply process. Consumer awareness of the food safety risk depends on the overall evaluation of the food quality and the impact of quickly developing food safety incidents upon consumers' behavior. If consumers believe that milk food safety problems seem likely to appear in the farm production processes, consumers' WTP to GAPmilk should be higher once this information becomes common knowledge. This paper projects that these two variables are positively correlated with the WTP. The specific definition of the variables, statistical analysis, and the expected direction of the results are listed in Table 3.

\section{Consumer's WTP and influence factors}

The model results show that the Log likelihood is 62.842 , and a statistical significant is in the level of $1 \%$, so the model does pass the maximum likelihood test.

\begin{tabular}{|c|c|c|c|c|}
\hline Varible & Definition & Average & S.E. & Expected direction \\
\hline \multicolumn{5}{|l|}{ 1. Individual characteristics } \\
\hline Gender & Male $=0$, Female $=1$ & 0.54 & 0.50 & + \\
\hline Education level & $\begin{array}{l}\text { Primary school and less }=1 \text {, Junior middle school=2, } \\
\text { highschool=3, college }=4 \text {, postgraduate }=5\end{array}$ & 3.49 & 0.90 & + \\
\hline Income & $\begin{array}{l}<35000 \mathrm{RMB}=, 35000-70000 \mathrm{RMB}=2,70000-150000 \\
\mathrm{RMB}=3,150000-300000 \mathrm{RMB}=4,300000 \mathrm{RMB} \leq=5\end{array}$ & 2.54 & 1.07 & + \\
\hline Preschooler & $\mathrm{Yes}=1, \mathrm{No}=0$ & 0.11 & 0.31 & + \\
\hline Elder over 60 & $\mathrm{Yes}=1, \mathrm{No}=0$ & 0.28 & 0.45 & + \\
\hline \multicolumn{5}{|l|}{ 2. Price characteristics } \\
\hline BID & $\begin{array}{l}\text { Consumers are asked if you are willing to pay an } \\
\text { additional price for the GAPmilk, the additional price are } \\
\text { ORMB, 0.3RMB, 0.7RMB, 1.2RMB, 1.8RMB, 2.5RMB, } \\
\text { 4RMB }\end{array}$ & 0.39 & 0.64 & - \\
\hline \multicolumn{5}{|c|}{ 3. Consumer's awareness and evaluation } \\
\hline Stage & $\begin{array}{l}\text { Most risky procedure or stage of food supply, Agricultural } \\
\text { production }=1 \text {, Others }=0\end{array}$ & 0.22 & 0.41 & + \\
\hline Risk & Valuation of food safety & 3.26 & 1.19 & + \\
\hline
\end{tabular}
Nagelkerke R Square is 0.452 , meaning the goodness of

Table 3. Model explanatory variables Description

Source: field survey by the authors. 
fit of the model for survey data is $45.2 \%$ (Table 4).

Bringing the coefficient of each variable in the model results into the equation (2), we will obtain consumers' WTP to GAPmilk at $0.37 \mathrm{RMB}$, which is $18.5 \%$ of the price of ordinary milk. The result of simple arithmetic average is $15 \%$. So we can see that both of two results are similar.

Although when using the same binary logistic regression model to calculate consumers' WTP, the overflow ratio results are quite different. The result of Wang et al. (2012) is 10\%. Liu et al. (2009) is 27.27\%, and Zhou and Peng (2006) is 335\%. In foreign researches on the subject the result of Buzby et al. (1995) is $38-138 \%$, and Boccaletti and Nardella (2000) is 10\%. Although the objectives of the various researches were different, the gap among the researches should primarily result from the differences in the samples, including questionnaire design, survey method and respondent.

There are four variables significantly affecting consumer's WTP. They are gender, income, the presence of preschoolers and the BID. Contrary to the expected results, in the case of other conditions being consistent, more men than women are willing to pay extra fees for GAPmilk. This result is different from Wang et al. (2012) and Liu et al. (2009).This may owe to men on the average having a higher income than women. Also men may have a stronger vanity than women, and may tend to be willing to pay more than women in the questionnaire interviews.

Consistent with the expected result, the consumer's income has a significant effect on WTP. The higher income possessed by the consumer, the greater the additional fee that the consumer would be likely to pay for GAPmilk. This result is consistent with Wang et al. (2012), Liu et al. (2009) and Zhou and Peng (2006).

Households with preschoolers are obviously much more willing to pay more for food safety. A household's WTP when elderly people over the age of sixty are present is not so obvious, however. Although the statis- tics show a positive willingness to pay extra for GAP milk, the result was not significant. Caring for the old and young is a traditional Chinese virtue. However there is an impact with the one child/one family policy. In most families the expenditures on children are much greater than on the elderly. The results are consistent with Wang et al. (2012). In the Zhou and Peng (2006)'s result the variable of preschooler is positive and significant too, but the variable of elder people is not significant and negative.

The positive coefficient of BID shows that the price of safe food and consumer's WTP is positively correlated. The more expensive the safe food is, the more consumers are willing to buy. The integrity regarding food safety is generally lacking in China. Consumers tend to buy higher quality food at greater prices in foreign supermarkets and department stores, rather than for just checking green organic certification. Part of the highincome earners motivation is the peace of mind on food safety through the purchase of high priced and higher quality food. In our samples the annual net income with $53 \%$ of respondents is greater than $70000 \mathrm{RMB}$, and $18 \%$ of the respondents is greater than $150000 \mathrm{RMB}$. These households have the ability to buy more expensive foods. This result is the same as Wang et al. (2012), but contrary to Liu et al. (2009) and Zhou and Peng (2006). Maybe at the time of the Zhou and Peng (2006) and Liu et al. (2009) surveys, people still had faith in the food safety certification, such as certification of green food and organic food certification. However in 2012, it is an indisputable fact that fewer and fewer people believe in those certifications.

Consistent with as Wang et al. (2012) and Zhou and Peng (2006), our research results show also that the level of education is not significant to the WTP of the safe food. However, the awareness of the food safety risks is not significant only in our study. National food safety incidents of large-scale dairy enterprises fre-

Table 4. Binary logistic regression on factors effecting WTP

\begin{tabular}{lrcccc}
\hline Variables & $\mathrm{B}$ & S.E. & Wald & df & Sig. \\
\hline Sex** & -1.52 & 0.70 & 4.74 & 1 & 0.03 \\
Education & 0.44 & 0.42 & 1.14 & 1 & 0.29 \\
Income*** & 1.35 & 0.44 & 9.27 & 1 & 0.00 \\
Children** & 2.01 & 0.96 & 4.36 & 1 & 0.04 \\
Elder & 0.56 & 0.78 & 0.52 & 1 & 0.47 \\
BID*** & 5.66 & 4.33 & 1.71 & 1 & 0.01 \\
Stage & -1.05 & 0.96 & 1.20 & 1 & 0.27 \\
Risk & 0.22 & 0.30 & 0.56 & 1 & 0.46 \\
Constant & -2.95 & 2.41 & 1.50 & 1 & 0.22 \\
\hline
\end{tabular}

Cases included in analysis: 290; Missing cases: 13; Total cases selected:303

Dependent variable: whether you are willing to buy the GAPmilk, with 277 cases $=1$, and 13 cases=0 Log likelihood=62.842, Nagelkerke R Square $=0.452$

Note: $* * *$ and $* *$ represent statistical significance in the level of $1 \%$ and $5 \%$, respectively.

Software: SPSS 18.0

Source: field survey by the authors. 
quently occurred, so that more and more consumers are concerned about the dangers of food safety. These incidents may cause people to be confused on trusting food safety. Because of that anomie, there may be reluctance for making additional payments to provide food safety certification.

\section{CONCLUSION AND DISCUSSION}

The results of the statistical analysis show that most people are concern about food safety; more than half of the respondents believe that existing food is not safe; $63 \%$ of the respondents worry about milk safety; $33.55 \%$ of the respondents think that residue from such sources as antibiotics and hormones is the most important factor to cause the milk food safety.

The results of the econometric analysis show that BID, gender, income and the presence of preschoolers are significant towards the consumer's WTP to GAPmilk; the average additional fee that consumer is willing to pay for GAPmilk is $0.37 \mathrm{RMB} / 205 \mathrm{ml}$, which is $18.5 \%$ of the price of ordinary milk. Although food safety incidents frequently occurred in dairy enterprises, the consumer's WTP is not as high as would be expected. The main reason could be that consumers lack the confidence to know and identify safe food. This result is similar to the research of Zhou and Nanseki (2013).

According to Chen et al. (2011) the GAP certification costs of a farm is typically about 22,000 RMB. By dividing the cost by the overflow price $0.37 \mathrm{RMB} / 250 \mathrm{ml}$, then multiplying by $250 \mathrm{ml}$, and finally dividing by 1000 , we will achieve the breakeven point which is 14,865 titer. If a dairy enterprise can produce and sell the GAP milk over the breakeven point, the farmer can make a profit. The nation-wide large-scale dairy enterprises such as Mengniu, Yili, Sanyuan and Guangming, and the production and sales in local dairy enterprises such as Chongqing Tianyou, Nanjing Weigang Dairy have production far greater than this number.

If a dairy enterprise truly produces safe milk, this reduces the information asymmetry between producers and consumers, and enhances consumer trust in the safety of milk. Safe milk market will then develop rapidly. Then consumers will be able to enjoy higher quality milk at higher prices.

Appendix: This paper is the research result of the food safety research group of Kyushu University East Asia Environmental Research Institutions.

\section{REFERENCES}

Boccaletti Stefano and Michael Nardella 2000 Consumer Willingness to Pay for Pesticide-free Fresh Fruit and Vegetables in Italy. International Food and Agribusiness Management Review, 3(3): 297-310

Buzby Jean C., Jerry R. Skees and Richard C. Ready 1995 Using Contingent Valuation to Value Food Safety: a Case Study of Grapefruit and Pesticide Residues. in Caswell, Julie A. (Ed.), In "Valuing Food Safety and Nutrition", Boulder, CO: Westview Press. pp. 278-287

Chen T., Chen L. and T. Nanseki 2011 Effect of ChinaGAP on Agricultural Products Export: Evidence from Companies in Shanghai. J. Fac. Agr., Kyushu Univ., 56(1): 171-176

Liu J., Wang K., Han J. 2009 Consumers' willingness to pay for food safety and its influencing factors. Jianghai academic journal, 3: 83-89

Ritson, Christopher and Li Wei Mai 1998 The Economics of Food Safety. Nutrition and Food Science, 98(5): 253-259

Wang Z. and Mao y. 2006 Urban consumers awareness level of the HACCP certification, acceptance, willingness to pay and its influencing factors- a case study of Haidian District, Beijing supermarket shoppers. China rural Survey, 5: 2-12

Wang Z., Li T., Zhu Y. 2012 Willingness to pay and the impact factors of the big city consumer on safe liquid milk-a case study of Beijing, Tianjin and Shijiazhuang. China price, 1: 51-55

Zeng Y., Xia W., Huang B. 2007 Consumers purchase, cognitive level of green food and its influencing factors-a case study of Beijing consumer survey. Consumer Economics, 2(23): 32-39

Zeng Y., Liu Y., Yu X. 2008 Hierarchical model of willingness to pay in the study of food safety- case study of Beijing consumers' willingness to pay of moon cake additives, Agro technical Economics, 1: 84-90

Zhou H., Nanseiki T. 2013 Consumers' Risk Awareness and Willingness to Pay for Certified Food. In "Food Safety and Agro-Environment in China: The Perceptions and Behaviours of Farmers and Consumers", Intech, 131-149

Zhou Y., Peng X. 2006 Consumer Willingness to Pay for Food Safety in Jiangsu Province China: A Case Study of Reduced Pesticide Residues B. Chinensis. China Economic Quarterly 5(4): 1319-1342 